\title{
BMJ Open Impact of COVID-19 on mobility and participation of older adults living in Hamilton, Ontario, Canada: a multimethod cohort design protocol
}

\author{
Marla K Beauchamp (D , , ${ }^{1}$ Brenda Vrkljan, ${ }^{1}$ Renata Kirkwood, ${ }^{1}$ Elisabeth Vesnaver, ${ }^{2}$ \\ Luciana G Macedo (D) , ${ }^{1}$ Heather Keller (D) , Janie Astephen-Wilson, ${ }^{4}$ \\ Nazmul Sohel, ${ }^{5}$ Tara Noble, ${ }^{1}$ Nicholas Dietrich, ${ }^{1}$ Paula Gardner, ${ }^{6}$ \\ K Bruce Newbold (D) , ${ }^{7}$ Darren Scott ${ }^{7}$
}

To cite: Beauchamp MK, Vrkljan B, Kirkwood R, et al. Impact of COVID-19 on mobility and participation of older adults living in Hamilton, Ontario, Canada: a multimethod cohort design protocol. BMJ Open 2021;11:e053758. doi:10.1136/ bmjopen-2021-053758

- Prepublication history and additional supplemental material for this paper are available online. To view these files, please visit the journal online (http://dx.doi.org/10.1136/ bmjopen-2021-053758).

Received 24 May 2021 Accepted 19 November 2021

Check for updates

(C) Author(s) (or their employer(s)) 2021. Re-use permitted under CC BY-NC. No commercial re-use. See rights and permissions. Published by BMJ.

For numbered affiliations see end of article.

Correspondence to Dr Marla K Beauchamp; beaucm1@mcmaster.ca

\section{ABSTRACT}

Introduction The novel COVID-19 required many countries to impose public health measures that likely impacted the participation and mobility of communitydwelling older adults. This protocol details a multimethod cohort design undertaken to describe short-term and medium-term changes to the mobility and participation of older Canadians living in the community rather than retirement facilities during the COVID-19 pandemic. Methods and analysis A longitudinal telephone (or online)-administered survey is being conducted with a random sample of older adults living within $20 \mathrm{~km}$ of McMaster University, Hamilton, Ontario, Canada, identified from census dissemination areas. Baseline data collection of community-dwelling older adults aged 65 years and over began in May 2020 with follow-ups at 3, 6, 9 and 12 months. The Late-Life Function and Disability Instrument and global rating of change anchors are the primary outcomes of interest. A subsample of respondents will participate in open-ended, semistructured interviews conducted over the telephone or through videoconference, to explore participants' lived experiences with respect to their mobility and participation during the pandemic. Descriptive statistics and quantitative approaches will be used to determine changes in mobility and social and personal participation, and associated personal and environmental factors. For the interviews, qualitative data will be analysed using descriptive phenomenology.

Ethics and dissemination Approval was obtained from the Hamilton Integrated Research Ethics Board of McMaster University (2020-10814-GRA). This study may inform the design of programmes that can support community-dwelling older adults during and after the COVID-19 pandemic. Findings will be disseminated through peer-reviewed publications and conferences focused on ageing.

\section{INTRODUCTION}

The emergence of SARS-CoV-2, also known as COVID-19, caused a pandemic with enormous economic, health and social repercussions
Strengths and limitations of this study

- This protocol was designed to describe the impact of COVID-19 and social distancing on the mobility and participation of community-dwelling older adults.

- The qualitative interviews will explore the lived experience of older adults and how their activities, mobility and social networks may have changed during the pandemic.

- The longitudinal nature of the study, with 3-month, 6-month, 9-month and 12-month follow-ups, will allow us to examine both short-term and mediumterm changes in mobility and participation in older adults as the pandemic unfolds.

- These data will inform the development of strategies that researchers and clinicians can use to minimise the adverse consequences of this pandemic on the lives of older adults.

- Given the timing of the study, we will be unable to comment with certainty on the usual mobility and participation levels of our sample prior to the pandemic, and responses could be subject to recall bias and social desirability. In addition, given the nature of the telesurvey, our study consists of entirely selfreported measures. Participants may not remember their previous health conditions or changes to their mobility. They may also over-rate their physical function and social status. To minimise bias, we opted to use validated self-reported questionnaires, selected an appropriate recall period (before the pandemic), and ensured our survey administrators and interviewers were well trained.

worldwide. ${ }^{1}$ The group most vulnerable to COVID-19 are older adults and those with chronic underlying health conditions. ${ }^{2}{ }^{3}$ Recent data indicate the mortality rate is $3.6 \%$ among those in their $60 \mathrm{~s}$, which increases to $8.0 \%$ and $14.8 \%$ for those in their $70 \mathrm{~s}$ and those aged 80 years and older, ${ }^{45}$ respectively. The WHO strongly recommends public 
health measures, including physical/social distancing and masking, as the primary means of prevention and slowing the spread of the virus. ${ }^{46}$ These measures suggest all individuals, particularly older people, avoid any physical contact with others beyond their household. Older adults living with chronic health conditions are at an even higher risk of complications from COVID-19 and, as such, Canada's and other countries' national public health agencies emphasise the importance of avoiding unnecessary trips outside the home. Although social distancing has shown to be effective in reducing the spread of COVID-19 and deaths due to this virus, ${ }^{6}$ the resulting impact of social isolation and reduced activity on the ageing population could be devastating. ${ }^{7}$

The importance of complying with social distancing and other public health measures during the pandemic has also impacted the usual patterns and routines of those who live in the community. ${ }^{4}$ Complying with these measures may mean a reduction in meaningful social contact and participation in life roles-a critical aspect of health recognised by the WHO. For older people, in particular, social isolation is often intertwined with feelings of loneliness, ${ }^{89}$ which can result in subjective feelings of anxiety and dissatisfaction with one's lack of meaningful connectivity with others. ${ }^{40}$ Although many older people live alone and engage less often in social gatherings, those in their cohort have been disproportionally affected by COVID-19. Furthermore, to comply with such measures, community-dwelling older adults may have essential items delivered to their home, such as groceries and medication, rather than go to a store, which means they may not be able to fully participate in their daily life activities and roles at a level with which they are satisfied.

Sustaining regular physical activity in later life has many known health benefits, including maintenance of muscle strength, mobility and self-care tasks. ${ }^{11}$ Older adults who are less active are at risk of becoming frail and deconditioned and may experience losses in physical function/mobility that further increase their risk of adverse outcomes such as falls and hospitalisation. Mobility limitation may additionally pose a strong barrier to home and community participation. ${ }^{12}$ Hence, it is crucial that we better understand the impact of pandemic-related public health measures on the everyday functioning and participation of community-dwelling older people.

The WHO International Classification of Functioning, Disability and Health (ICF) defines participation as the 'involvement in a life situation' and recognises that restrictions in home and community life can lead to dysfunction and disability. ${ }^{13}$ Within the ICF, the wide scope and complexity of mobility and its impact on health is also acknowledged, which ranges from moving one's limb or transferring from a chair, to getting around the community using various forms of transportation. Key factors known to influence mobility and participation in later life are physical and functional declines in health as well as contextual barriers that prevent access to activities. ${ }^{14}$ Thus, we developed a longitudinal survey to understand the short-term and medium-term impact of COVID-19 and associated public health measures on the mobility and participation of community-dwelling older adults. Our protocol also includes qualitative interviews with a subsample of respondents to explore their lived experiences of participation while pandemic-related public health restrictions are in place. During the interviews, participants will be asked to elaborate on their participation in activities pre-pandemic, during, as well as post-pandemic.

By understanding the impact of the pandemic on mobility and participation of community-dwelling older adults, findings from this study can inform interventions and other strategies that can mitigate the health and social-related consequences of the pandemic as well as prioritise scarce resources to those most at risk. In March 2020, the WHO reminded governments to support interventions to ensure older people can access what is needed during this pandemic to maintain their well-being. Such interventions could include innovations that support social connectivity with families and friends, how to get help for everyday needs, and recommendations on how to maintain their mental and physical health when stringent public health measures are in place. ${ }^{15}$ We anticipate the results of both the survey and interviews will inform targeted interventions that support the health and mobility of older adults living in the community during the current and future pandemics, or any other circumstances that challenge or disrupt their participation in everyday life.

\section{Objectives}

To describe changes in mobility and participation among community-dwelling older adults during the COVID-19 pandemic, and the associated personal and environmental factors that can influence engagement in everyday life and impact mobility, we address the following questions:

1 . What are the short-term and medium-term mobility and participation implications for older adults during the pandemic crisis?

2. What person-level characteristics and environmental factors are associated with different levels of mobility and participation of older adults during this pandemic?

3. What personal and environmental factors (eg, social support, nutrition risk, resilience) are associated with changes in physical function and participation scores at 3-month, 6-month, 9-month and 12-month followups?

4. What is the lived experience of community-dwelling older adults who reported higher levels of distress during the pandemic and how do they perceive their current level of participation in everyday activities in comparison with how they managed these activities before the pandemic, including factors that have influenced their ability to manage these activities (or not) during the pandemic due to the public health restrictions in place? 


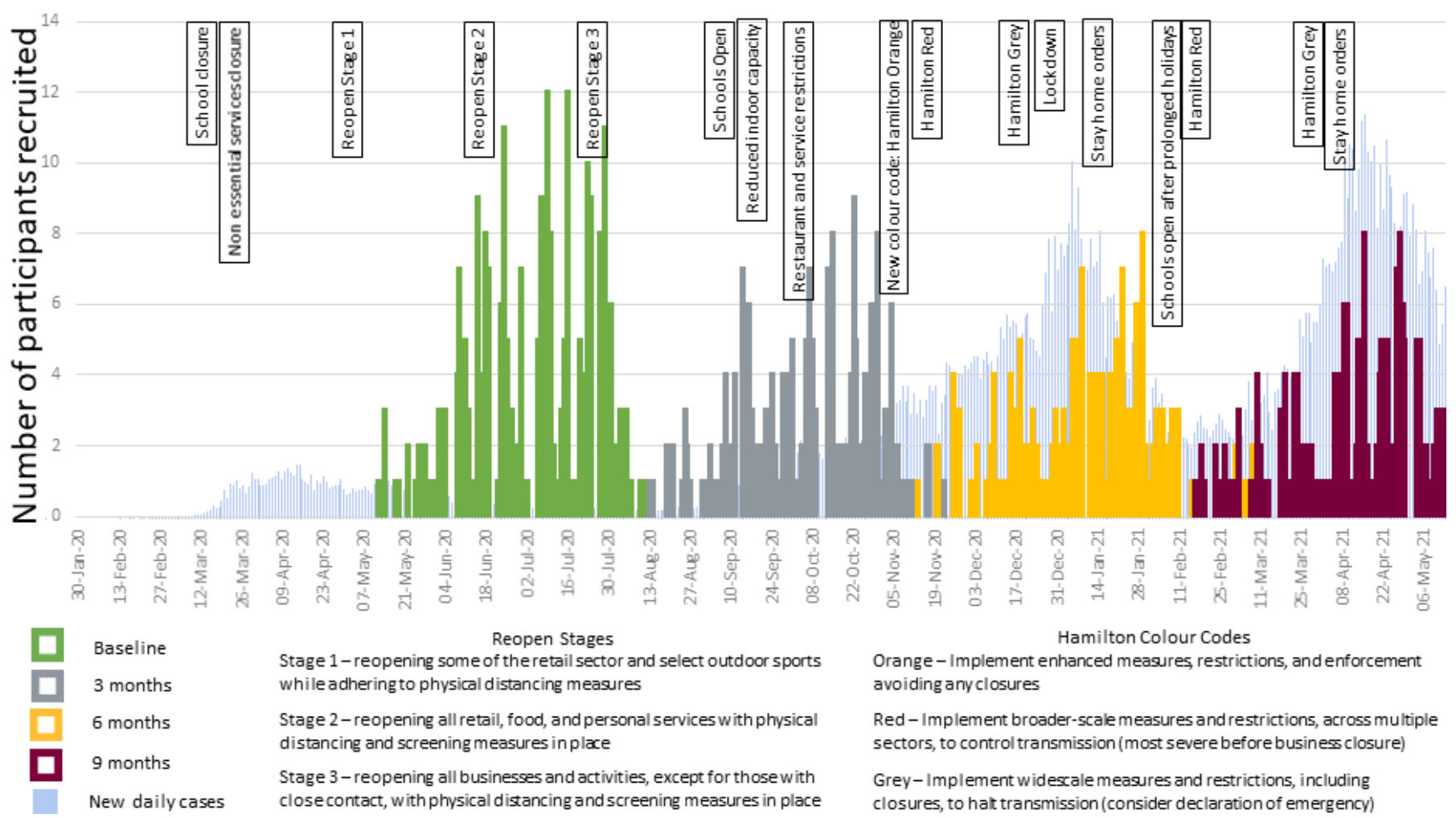

Figure 1 IMPACT Study timeline showing the number of participants recruited at baseline and follow-ups, the daily number of cases of COVID-19 and the measures taken by the Ontario Government to contain the spread of the disease.

5. How do older adults envision what their daily lives and corresponding participation in everyday activities will look like after the pandemic when associated restrictions are lifted?

This study will also serve as a platform for additional analyses not limited to those described above.

\section{METHODS AND ANALYSIS}

A longitudinal telephone-administered survey, with the option to complete the survey online through a link sent by email, is being conducted with a random sample of older adults living in Hamilton, Ontario, Canada. Baseline data collection began on 12 May 2020 at the end of the first wave of the pandemic and enrolment continued until 5 August 2020. The 3-month follow-up survey was initiated in August 2020, the second follow-up at 6 months that started in November 2020, and we are currently completing the 9-month follow-up that started in February 2021. The 12-month follow-up is scheduled to run date to date, 2021. Figure 1 shows the study timeline and the respective lockdown stages in the Hamilton, Ontario area.

Participants were initially contacted by phone and asked if they consented to be contacted again every 3 months after the first survey was administered. In addition to the survey, a subsample of survey respondents will be contacted to participate in an open-ended, semistructured interview. Further details on the target sample for this qualitative study, including recruitment as well as other procedures, are outlined below.

\section{Participants and recruitment}

Participants were eligible for the study if they were community-dwelling adults (ie, living independently in the community, aged 65 years or older, able to provide consent and live in the greater Hamilton area, Ontario). Exclusion criteria included not living independently in the community (ie, live in a nursing home) or the presence of a severe and uncorrectable cognitive, visual, or hearing impairment that would preclude a participant's ability to complete the survey. At the time of agreeing to complete the survey, participants were asked if they could be contacted for future studies. A list of those who were agreeable to be contacted will be generated as potential participants for the interview study. The inclusion and exclusion criteria for the interviews are the same as those for the survey.

\section{Sample size}

Postal codes were selected based on distance from McMaster University, where participants were categorised into four groups: $\leq 5 \mathrm{~km}, 5-10 \mathrm{~km}, 10-15 \mathrm{~km}$ and $15-20 \mathrm{~km}$. To increase the probability of identifying older aged people (ie, age $\geq 65$ years) in the community, we ranked them from highest to lowest proportion of age. We used 2016 census population data to extract the proportion of the older population at each dissemination area and linked them to the postal codes. We selected the 
top-ranked postal codes and sent them to ASDE Survey Sampler ${ }^{16}$ which, in March 2020, provided us with 10000 residential phone numbers equally distributed for each distance category, that is, 2500 per group. A total of 784 postal codes were selected which cover a population of 43664 from which 21320 were listed as 65 years old and above. In the first set of phone numbers, all residential phone numbers $(\mathrm{n}=6107)$ from 288 postal codes were selected that cover a population of 22769 , where 12990 are aged $\geq 65$ years. In the second set of numbers, a random sample of 3893 numbers from additional 345 postal codes were selected. In order to detect a minimally clinically important difference of 2.5 points ${ }^{17}$ (corresponding to an effect size of 0.195) in scores of Late-Life Function and Disability Instrument-Function component at each follow-up, we used an SD of $6.4,{ }^{18}$ a power of $95 \%$, an alpha level of 0.05 , and a sample size of 216 participants was required. Accounting for $20 \%$ loss to follow-up, the final sample size required was 260 participants. Consecutive phone numbers from our randomised list of 10000 numbers were called until the required sample of 260 participants was obtained. Recruitment began on 12 May and ended on 5 August 2020, with 272 participants included in the baseline survey.

Data from the Impact of Event Scale-Revised (IES-R), a measure of subjective distress, will be used to identify people experiencing a range of psychological distress during the pandemic. It is anticipated that $10 \%$ of the world's population will experience post-traumatic stress disorder due to the pandemic. ${ }^{19}$ Participants for a qualitative substudy will be selected using IES-R scores by applying a combination of maximum variation in these scores as well as extreme case purposive sampling strategies. The aim is to have $50 \%$ gender representation as well as other demographics reflected in the interview sample, including ethnicity, education, socioeconomic status and using the full age range of those surveyed. We expect $30-40$ participants will participate in the interviews. ${ }^{20}$

\section{Patient and public involvement}

The participants in this study were not involved in the development of the research question or design of this study, recruitment or conduct of the study. We will disseminate our findings through news blasts and presentations to participants, policymakers and the community.

\section{Survey item development}

The ICF classification of body structures and functions, activities, and participation as well as personal and contextual factors were used to consider various items to be included in the survey. These items were developed based on the research team's knowledge and expertise in particular areas (eg, pain, nutrition, falls, driving transportation) and where possible, by using available structured and validated questionnaires to capture items. Selected demographic and social characteristics items are presented in table 1. Questions about anxiety and depression, ${ }^{21}$ social support $^{22} 23$ and loneliness, ${ }^{21}{ }^{24}$ physical activity, such as type and frequency, ${ }^{25}$ and the participants' driving status are also included in the survey. Neighbourhood and life space, ${ }^{26}$ and how often they had participated in out-ofhome activities in the past month are also included.

\section{Changes in activity and participation}

A global rating of change scale (GRC) was developed to capture participant-reported changes in activities (mobility, physical activity) and participation (social and personal). GRC scales are a simple and quick method to assess change in research and clinical settings and are widely accepted as an external criterion to identify people for whom important change has or has not occurred..$^{27} 28$ We asked participants to subjectively rate their perceived change in specific participation and mobility domains (for example, moving around their home, taking care of errands, taking care of their health) since social distancing was required due to COVID-19, using a 5-point Likert scale (much worse, a little bit worse, stayed about the same, a little bit better, much better) (table 2).

\section{COVID-19 awareness and change in behaviour}

Questions about COVID-19 awareness and change in behaviour due to the pandemic crisis were included in the survey. We also asked if respondents had contracted COVID-19, had concerns about becoming infected with COVID-19 and concerns about seeking medical attention for reasons related to COVID-19.

\section{Questionnaires}

Table 3 describes the questionnaires included in the survey. Social and demographic characteristics of the participants were collected during baseline. The questionnaires conducted at baseline and during the follow-ups address functional, disability and mobility measures, anxiety, levels of distress, resilience, nutrition risk, pain and environmental factors. We used the ICF framework to guide the questionnaires' selections, and questionnaires have been validated with the older population.

\section{Survey testing and training}

Field testing of the survey was completed with older adult volunteers to gauge timing and difficulty of the questions and the survey was revised accordingly. Administration of the survey was deemed to take $45-60 \mathrm{~min}$, and $30 \mathrm{~min}$ subsequently for each follow-up wave. Please see online supplemental appendix A for more information on the instruments used in the baseline survey.

Once the design of survey was finalised, eight individuals (five undergraduate student volunteers, one MSc student volunteer, one MSc student and one PhD student) were trained to administer the survey by the study coordinator. An individual teleconferencing session (using the Zoom platform) was arranged with each survey administrator to review the study protocol and how to enter data into the online data portal (ie, REDCap). The training session included practising the consent process with the research coordinator. Different scenarios were also roleplayed during this session to ensure different issues that 
Table 1 Selected sociodemographic and health status characteristics of the survey participants obtained at baseline

\begin{tabular}{|c|c|}
\hline Variables & Description \\
\hline Sex & Male/female \\
\hline Age (years) & $\geq 65$ \\
\hline Country of birth & If not Canada, what year did you first come to Canada to live? \\
\hline Racial background & $\begin{array}{l}\text { White, Chinese, South Asian, black, Filipino, Latin American, Southeast Asian, Arab, West Asian, } \\
\text { Japanese, Korean, North American Indian, Inuit and Métis }\end{array}$ \\
\hline Educational level & $\begin{array}{l}\text { Less than secondary school completed } \\
\text { Secondary school graduation but no post-secondary education } \\
\text { Some post-secondary education } \\
\text { Post-secondary degree/diploma }\end{array}$ \\
\hline & $\begin{array}{l}\text { Spouse/partner } \\
\text { Other family member(s) } \\
\text { Friends } \\
\text { Roommate(s) } \\
\text { Tenant(s) }\end{array}$ \\
\hline \multirow[t]{2}{*}{ Type of dwelling } & What type of dwelling do you currently live in? \\
\hline & $\begin{array}{l}\text { House (eg, single detached, semidetached, duplex or townhouse) } \\
\text { Apartment or condominium } \\
\text { Seniors' housing (eg, retirement home, senior lodges, senior residences, assisted living) } \\
\text { Institution (eg, long-term care facility, nursing home) } \\
\text { Mobile home, hotel, rooming house or group home }\end{array}$ \\
\hline $\begin{array}{l}\text { Self-rated general } \\
\text { health and self-rated } \\
\text { mental health }\end{array}$ & $\begin{array}{l}\text { Excellent } \\
\text { Very good } \\
\text { Good } \\
\text { Fair } \\
\text { Poor }\end{array}$ \\
\hline Smoking status & $\begin{array}{l}\text { Daily (ie, at least one cigarette every day for the past } 30 \text { days) } \\
\text { Occasionally (ie, at least one cigarette in the past } 30 \text { days, but not every day) } \\
\text { Not at all (ie, you did not smoke at all in the past } 30 \text { days) }\end{array}$ \\
\hline $\begin{array}{l}\text { Self-reported chronic } \\
\text { conditions }\end{array}$ & $\begin{array}{l}\text { Cataracts/glaucoma/bowel and urinary incontinence/osteoarthritis/osteoporosis/back pain/chronic } \\
\text { pain/dementia/Alzheimer's/multiple sclerosis/stroke/transient ischaemic attack/cerebrovascular } \\
\text { accident/traumatic brain injury/Parkinson's/heart disease/peripheral arterial disease/hypertension/ } \\
\text { angina/heart attack/aortic valve stenosis/anxiety disorder/mood disorder/clinical depression/ } \\
\text { asthma/Chronic obstructive pulmonary disease/bronchitis/emphysema/kidney disease or failure/ } \\
\text { diabetes/cancer }\end{array}$ \\
\hline
\end{tabular}

Continued 
Table 1 Continued

\begin{tabular}{|c|c|}
\hline Variables & Description \\
\hline Physical activity & $\begin{array}{l}\text { (1) Over the past } 7 \text { days, how often did you take a walk outside your home or yard for any reason? } \\
\text { For example, for fun or exercise, walking to work, walking the dog, etc. (2) Over the past } 7 \text { days, how } \\
\text { often did you do any exercises, specifically to increase muscle strength and endurance, such as } \\
\text { lifting weights or push-ups, etc? } \\
\text { Never } \\
\text { Seldom (1-2 days) } \\
\text { Sometimes ( } 3-4 \text { days) } \\
\text { Often (5-7 days) }\end{array}$ \\
\hline $\begin{array}{l}\text { Pain location and } \\
\text { stiffness }\end{array}$ & $\begin{array}{l}\text { In the last month, have you had any musculoskeletal problems or chronic pain (ex: back pain, neck } \\
\text { pain, knee pain, stiffness)? }\end{array}$ \\
\hline Self-rated pain levels & Likert scale from 0 to 10 \\
\hline
\end{tabular}

could arise with a participant during the consent process and administering the survey (eg, asking lots of questions, confusion over study participation, mental health distress, etc).

An operations manual summarising the points discussed during training alongside detailed instructions on using REDCap, frequently asked questions and troubleshooting tips were provided to those administering the survey. The study coordinator also held biweekly Zoom meetings with the team to discuss progress and concerns.

The trained survey administrators contacted participants by telephone. Participants who provided verbal consent to participate in the full survey had their responses entered by the interviewers using REDCap web-based survey software. Participants who opted to complete the survey online received the survey through REDCap by email.

\section{Interview guide development and training}

The interview guide has been developed to explore the lived experiences of community-dwelling older adults who were profiled based on their self-reported level of distress on the survey (ie, IES-R score). Interview questions explore perceptions of participants regarding their ability to engage in activities during the pandemic with public health restrictions in place and to reflect on changes, if any, in their ability to participate in such activities. To invoke such reflections, participants will be asked at the outset of the interviews to think of their life as though they were making a movie trilogy or three-part miniseries where the first part of their trilogy is their everyday life 'before COVID-19'. The second part of the trilogy refers to their life after the initial lockdown in March 2020 to how they are managing at the time of survey. For the third and final part, we will ask participants to look ahead to consider what their life might be like in the post-pandemic

Table 2 Changes in activity and participation questions since COVID-19

\section{Questions}

I would like to know about how your perceived functional ability and daily activities have changed since social/physical distancing began due to COVID-19.

Your ability to move around in your home (such as walking, climbing stairs) has become...

Your ability to engage in housework activity (such as dusting, washing dishes and vacuuming) has become...

Your ability to engage in physical activity (walking, exercise, working out) has become...

Your ability to keep in touch with others (through letters, cell phone/ phone or email) has become...

Your ability to take care of your health (such as managing daily medications, following a diet, cooking your own meals, bathing, dressing and toileting) has become...

Your ability to take care of your errands (such as buying groceries or taking care of finances) has become...

Your ability to participate in the community and maintain a social life (eg, volunteer, connect with others) has become...

\section{Scoring}

You can choose a response from the following 5-point scale

1-much worse

2-a little bit worse

3-stayed about the same

4-a little bit better

5-much better 
Table 3 Summary of the structured questionnaires in the survey

\begin{tabular}{|c|c|}
\hline Questionnaires & Description \\
\hline $\begin{array}{l}\text { The Late-Life Function } \\
\text { and Disability Instrument } \\
\text { (LLFDI) }\end{array}$ & $\begin{array}{l}\text { The LLFDI will be used to assess function/mobility and participation, }{ }^{31}{ }^{32} \text { consistent with the WHO } \\
\text { and Nagi disablement frameworks. The function domain measures limitations in the person's } \\
\text { ability to perform discrete mobility tasks or activities such as how much difficulty a person has, for } \\
\text { example, going up and downstairs, walking a mile, putting on and taking off a jacket, etc. }{ }^{31} \text { The } \\
\text { disability domain refers to a person's performance of life roles (participation). The participants' } \\
\text { responses are based on how often they do a certain activity and to what extent they feel limited } \\
\text { when performing a specific activity. The LLFDI has concurrent and predictive validity with other } \\
\text { functional performance measures in older adults. }{ }^{18} \text { Raw scores are transformed to scaled } \\
\text { scores from } 0 \text { to } 100 \text { with higher scores indicating better function/participation. The MCID for } \\
\text { small changes on the LLFDI overall function component is } 2 \text { points out of } 100 \text {, and } 5 \text { points for } \\
\text { substantial change. }{ }^{17}\end{array}$ \\
\hline $\begin{array}{l}\text { EuroQol 5D-5L (EQ-5D- } \\
5 \mathrm{~L})^{3334}\end{array}$ & $\begin{array}{l}\text { The EQ-5D-5L is a generic instrument for describing health status. It defines health in terms of five } \\
\text { dimensions: mobility, self-care, usual activities, pain/discomfort and anxiety/depression. }{ }^{33} 34 \text { The } \\
\text { response options are of five levels, from no, slight, moderate, severe, to extreme problems. The } \\
\text { scale has shown adequate content and face validity. }{ }^{34}\end{array}$ \\
\hline $\begin{array}{l}\text { Impact of Event Scale } \\
(\text { IES) }\end{array}$ & $\begin{array}{l}\text { The IES is widely used to assess a variety of traumas. }{ }^{36} \text { The scale has adequate test-retest } \\
\text { reliability ( } r=0.87) \text {, with adequate construct, content and convergent validity with a variety of other } \\
\text { measures of distress. }\end{array}$ \\
\hline $\begin{array}{l}\text { Brief Resilience Scale } \\
(\text { BRS })^{37}\end{array}$ & $\begin{array}{l}\text { The BRS comprises } 6 \text { items, each rated on a } 5 \text {-point scale }(1-5) \text {, with higher scores reflecting } \\
\text { greater resilience. }{ }^{37} \text { The BRS has shown acceptable internal consistency, reliability and concurrent } \\
\text { validity as an instrument to measure resilience in community-dwelling older adults. }{ }^{37-39}\end{array}$ \\
\hline $\begin{array}{l}\text { Seniors in the } \\
\text { Community }{ }^{40} \text { : Risk } \\
\text { Evaluation for Eating and } \\
\text { Nutrition (SCREEN-8) }\end{array}$ & $\begin{array}{l}\text { The SCREEN- } 8 \text { is a valid and reliable screening tool to detect nutrition risk in community- } \\
\text { dwelling older adults and is widely used in national surveys. }{ }^{41} 42 \text { The instrument is composed of } 8 \\
\text { questions, weight change (ie, loss or gain), appetite and swallowing difficulty and the total score } \\
\text { ranges from } 0 \text { to } 48 \text {. If the score is }<38 \text {, it indicates that a person is positive for nutrition risk. }{ }^{40}\end{array}$ \\
\hline Musculoskeletal pain ${ }^{43} 44$ & $\begin{array}{l}\text { The Numeric Pain Scale is a valid and reliable tool to evaluate musculoskeletal pain levels. } \\
\text { Participants are asked to rate their level of pain on a scale from } 0 \text { to } 10 \text { where } 0 \text { is no pain and } 10 \\
\text { is worse pain possible. }\end{array}$ \\
\hline
\end{tabular}

MCID, minimally clinically important difference.

period. This trilogy approach has been used successfully to examine changes in daily life following a major and unexpected personal issue, such as being diagnosed with a life-threatening illness, where such circumstances can disrupt or challenge a person's ability to engage in established activities and daily routines. ${ }^{29}$

The aim of the interviews in the current study is to further understand why some community-dwelling older adults have been able to more easily navigate the circumstances imposed by the pandemic, whereas others had more difficulty. The interview guide was piloted with three older adults to ensure the clarity of the questions and estimated time required for participation. Two research assistants have been trained to conduct the interviews, which included reviewing the interview guide, consent process and role-playing potential challenges that might arise. A manual was created and provided interviewers with an overview of key information required to undertake this qualitative study. Each interviewer has given a copy of this manual.

Survey respondents who affirmed their interest in being involved in other research studies and who meet criteria for sample selection as described above will be contacted by telephone to ask about participating in the interview study. Those who verbally consent will have an interview booked at a time that is convenient for them and the researcher. The interview will take approximately $45-60 \mathrm{~min}$. Interviews will be conducted by trained members of the research team by telephone or videoconference (ie, Zoom) and are expected to be conducted in the months of March, April and May of 2021. Interviews will be audio-recorded and professionally transcribed. The transcriptionist signed an oath of confidentiality which was provided to the ethics board in a study update.

\section{Data analysis}

Descriptive statistics, means with SDs and percentage frequencies will be calculated for all participants' characteristics and survey responses. Associations between participant characteristics and responses to COVID-19 questions will be examined using $\chi^{2}$ tests, t-tests and repeated measures. Analysis of variance will be used to examine changes in mobility and in participation over time. Multivariate linear regression models will be used to examine the factors associated with function and disability scores. IBM SPSS V.26 will be used for analysis and statistical significance will be set at $\mathrm{p}<0.05$.

For the interviews, the data will be analysed using descriptive phenomenology, as per Colaizzi's ${ }^{30}$ recommended approach, consisting of seven steps involving 
two investigators from the research team: (1) participant descriptions of the phenomenon are examined; (2) significant statements that pertain to the phenomenon are extracted; (3) meanings for these significant statements are identified; (4) categorising these statements into clusters of themes across participants; referring back to original transcriptions for validation and comparing across participant; (5) creating overarching descriptions of the phenomena that may involve bridging of themes and emerging conceptualisations; (6) validation findings, by returning to some participants to ask how the findings compare with their lived experiences (ie, member checking); and finally, (7) incorporating any changes offered by participants, where appropriate. When no new information emerges from analysing the interviews, the two investigators will meet to determine if data saturation has been achieved. The final thematic framework will also be audited by another investigator from the research team $(\mathrm{EV})$ who is not directly involved in data collection or coding.

\section{Data management}

All data will be saved on REDCap which is housed on McMaster University network servers and requires a user name and password to access which can only be granted by the study coordinator. Only the investigators will have access to the data. Each participant was assigned a unique identifier and all data sources will be de-identified and coded with this unique identifier. The interview recordings will be transcribed verbatim and stripped of identifying information and stored on a network server at the university that is also password protected.

\section{Ethics and dissemination}

The Hamilton Integrated Research Ethics Board of McMaster University approved this study on 4 May 2020 (2020-10814-GRA). Informed consent is obtained by phone prior to the commencement of the questionnaire. Participants are advised that they can receive a copy of the consent form via email or mail for their records. For the qualitative interviews, respondents on the survey who consented to be contacted for future studies and who meet sampling criteria will be contacted by phone to receive information about the purpose of the interview, the process of the interviews by telephone or through online video-conference (Zoom), potential risks and benefits of participating, consideration of participant confidentiality, voluntary participation and to confirm inclusion criteria. Prior to the interview, the participant will be sent a copy of the consent form either by email or by regular mail.

Findings from this study have the potential to inform our understanding of interventions, including community resources and strategies, that could be put in place to support community-dwelling older adults during COVID-19 and beyond, particularly if another major issue, such as a future pandemic, were to arise. Results from both the survey and interviews will deepen our understanding of the lived experiences of community-dwelling older adults during the pandemic and the factors that have influenced their ability to manage their everyday activities and mobility under these challenging circumstances. Outcomes will be shared with the academic community through peer-reviewed publications, webinar, as well as national and international conference presentations, including posters.

\section{Author affiliations}

${ }^{1}$ School of Rehabilitation Science, McMaster University, Hamilton, California, Canada ${ }^{2}$ School of Epidemiology and Public Health, University of Ottawa, Ottawa, Ontario, Canada

${ }^{3}$ Department of Kinesiology, University of Waterloo, Waterloo, Ontario, Canada ${ }^{4}$ Department of Surgery, McMaster University, Hamilton, California, Canada ${ }^{5}$ Department of Clinical Epidemiology and Biostatistics, McMaster University, Hamilton, California, Canada

${ }^{6}$ Department of Communication Studies and Multimedia, McMaster University, Hamilton, California, Canada

${ }^{7}$ School of Earth, Environment \& Society, McMaster University, Hamilton, California, Canada

Twitter Janie Astephen-Wilson @JanieLAWilson

Acknowledgements We would like to thank Anna Bhatti, Ruth Chen, Stephanie Civiero, Natalie Constantin, Cassandra D'Amore, Vincenza Gruppuso, Vishal Mokashi, Ken Nguyen and Cindy Wei for their support with the survey.

Contributors $\mathrm{MB}$ conceived of the survey and $\mathrm{BV}$ did the qualitative interviews. MB, BV, RK, LM, EV, HK, JA-W, NS, PG, KBN and DS designed the study. MB, BV and RK wrote the protocol. NS was responsible for the sampling frame, and RK and $\mathrm{MB}$ determined the study sample size. TN trained the research assistants and coordinated the overall study. ND and BV developed the interview guide to explore the lived experiences, and ND is currently conducting the interviews.

Funding This project is supported by funds from the Labarge Centre for Mobility on Aging within the McMaster Institute for Research on Aging (MIRA). Grant number is not applicable. MB is funded by a Canada Research Chair in Mobility, Aging and Chronic Disease.

Competing interests None declared.

Patient consent for publication Not required.

Provenance and peer review Not commissioned; externally peer reviewed.

Supplemental material This content has been supplied by the author(s). It has not been vetted by BMJ Publishing Group Limited (BMJ) and may not have been peer-reviewed. Any opinions or recommendations discussed are solely those of the author(s) and are not endorsed by BMJ. BMJ disclaims all liability and responsibility arising from any reliance placed on the content. Where the content includes any translated material, BMJ does not warrant the accuracy and reliability of the translations (including but not limited to local regulations, clinical guidelines, terminology, drug names and drug dosages), and is not responsible for any error and/or omissions arising from translation and adaptation or otherwise.

Open access This is an open access article distributed in accordance with the Creative Commons Attribution Non Commercial (CC BY-NC 4.0) license, which permits others to distribute, remix, adapt, build upon this work non-commercially, and license their derivative works on different terms, provided the original work is properly cited, appropriate credit is given, any changes made indicated, and the use is non-commercial. See: http://creativecommons.org/licenses/by-nc/4.0/.

\section{ORCID iDs}

Marla K Beauchamp http://orcid.org/0000-0003-2843-388X

Luciana G Macedo http://orcid.org/0000-0002-1840-2951

Heather Keller http://orcid.org/0000-0001-7782-8103

K Bruce Newbold http://orcid.org/0000-0002-6441-7863

\section{REFERENCES}

1 World Health Organization. Coronavirus disease 2019 (COVID-19) Situation Report-79; 2020.

2 Morley JE, Vellas B. COVID-19 and older adult. J Nutr Health Aging 2020;24:364-5. 
3 Kuwahara K, Kuroda A, Fukuda Y. COVID-19: active measures to support community-dwelling older adults. Travel Med Infect Dis 2020;36:101638.

4 Brooke J, Jackson D. Older people and COVID-19: isolation, risk and ageism. J Clin Nurs 2020;29:2044-6.

5 Shahid Z, Kalayanamitra R, McClafferty B, et al. COVID-19 and older adults: what we know. J Am Geriatr Soc 2020;68:926-9.

6 Nussbaumer-Streit B, Mayr V, Dobrescu Al, et al. Quarantine alone or in combination with other public health measures to control COVID-19: a rapid review. Cochrane Database Syst Rev 2020;4:CD013574.

7 Usher K, Bhullar N, Jackson D. Life in the pandemic: social isolation and mental health. J Clin Nurs 2020;29:2756-7.

8 Berg-Weger M, Morley JE. Loneliness in old age: an Unaddressed health problem. J Nutr Health Aging 2020;24:243-5.

9 Shankar A, McMunn A, Demakakos P, et al. Social isolation and loneliness: prospective associations with functional status in older adults. Health Psychol 2017;36:179-87.

10 Gale CR, Westbury L, Cooper C. Social isolation and loneliness as risk factors for the progression of frailty: the English longitudinal study of ageing. Age Ageing 2018;47:392-7.

11 Seguin R, LaMonte M, Tinker L, et al. Sedentary Behavior and Physical Function Decline in Older Women: Findings from the Women's Health Initiative. J Aging Res 2012;2012:1-10.

12 Hand CL, Howrey BT. Associations among neighborhood characteristics, mobility limitation, and social participation in late life. $J$ Gerontol B Psychol Sci Soc Sci 2019;74:546-55

13 World Health Organization Geneva. Towards a common language for functioning, disability and health: ICF. International classification 1149, 2002: 1-22.

14 Duppen D, Lambotte D, Dury S, et al. Social participation in the daily lives of frail older adults: types of participation and influencing factors. J Gerontol B Psychol Sci Soc Sci 2020;75:2062-71.

15 Nicol GE, Piccirillo JF, Mulsant BH, et al. Action at a distance: geriatric research during a pandemic. J Am Geriatr Soc 2020;68:922-5

16 ASDE solutions, for your organization. Available: http:// surveysampler.com

17 Beauchamp MK, Ward RE, Jette AM, et al. Meaningful change estimates for the late-life function and disability instrument in older adults. J Gerontol A Biol Sci Med Sci 2019;74:556-9.

18 Sayers SP, Jette AM, Haley SM, et al. Validation of the late-life function and disability instrument. J Am Geriatr Soc 2004;52:1554-9.

19 Soloveva NV, Makarova EV, Kichuk IV. Coronavirus syndrome: COVID-19 psychotrauma. Eur J Trans/ Myol 2020;30:9302.

$20 \mathrm{Sim}$ J, Saunders B, Waterfield J, et al. Can sample size in qualitative research be determined a priori? Int J Soc Res Methodol 2018:21:619-34.

21 Zhang W, O'Brien N, Forrest Jl, et al. Validating a shortened depression scale (10 item CES-D) among HIV-positive people in British Columbia, Canada. PLoS One 2012;7:40793.

22 Zucoloto ML, Santos SF, Terada NAY, et al. Construct validity of the Brazilian version of the medical outcomes study social support survey (MOS-SSS) in a sample of elderly users of the primary healthcare system. Trends Psychiatry Psychother 2019;41:340-7.

23 Priede A, Andreu Y, Martínez P, et al. The factor structure of the medical outcomes Study-Social support survey: a comparison of different models in a sample of recently diagnosed cancer patients. $J$ Psychosom Res 2018;108:32-8.
24 Irwin M, Artin KH, Oxman MN. Screening for depression in the older adult: criterion validity of the 10-item center for epidemiological studies depression scale (CES-D). Arch Intern Med 1999;159:1701-4

25 Logan SL, Gottlieb BH, Maitland SB, et al. The physical activity scale for the elderly (PASE) questionnaire; does it predict physical health? Int J Environ Res Public Health 2013;10:3967-86.

26 Stalvey BT, Owsley C, Sloane ME, et al. The life space questionnaire: a measure of the extent of mobility of older adults. Journal of Applied Gerontology 1999;18:460-78.

27 Kamper SJ, Maher CG, Mackay G. Global rating of change scales: a review of strengths and weaknesses and considerations for design. $J$ Man Manip Ther 2009;17:163-70.

28 Beninato M, Fernandes A, Plummer LS. Minimal clinically important difference of the functional gait assessment in older adults. Phys Ther 2014;94:1594-603.

29 Vrkljan BH, Miller-Polgar J. Meaning of occupational engagement in life-threatening illness: a qualitative pilot project. Can J Occup Ther 2001;68:237-46.

30 Colaizzi PF. Psychological research as the phenomenologist views it. In: Existential phenomenological alternatives for psychology, 1978: 48-71.

31 Jette AM, Haley SM, Coster WJ, et al. Late life function and disability instrument: I. development and evaluation of the disability component. J Gerontol A Biol Sci Med Sci 2002;57:M209-16.

32 Haley SM, Jette AM, Coster WJ, et al. Late life function and disability instrument: II. development and evaluation of the function component. J Gerontol A Biol Sci Med Sci 2002;57:M217-22.

33 Xie F, Pullenayegum E, Gaebel K, et al. A time Trade-off-derived value set of the EQ-5D-5L for Canada. Med Care 2016;54:98-105.

34 Herdman M, Gudex C, Lloyd A, et al. Development and preliminary testing of the new five-level version of EQ-5D (EQ-5D-5L). Qual Life Res 2011;20:1727-36.

35 Sundin EC, Horowitz MJ. Impact of event scale: psychometric properties. Br J Psychiatry 2002;180:205-9.

36 Horowitz M, Wilner N, Alvarez W. Impact of event scale: a measure of subjective stress. Psychosom Med 1979;41:209-18.

37 Smith BW, Dalen J, Wiggins K, et al. The brief resilience scale: assessing the ability to bounce back. Int J Behav Med 2008; 15:194-200.

38 Wagnild GM, Young HM. Development and psychometric evaluation of the resilience scale. J Nurs Meas 1993;1:165-78.

39 Cosco TD, Kaushal A, Richards M, et al. Resilience measurement in later life: a systematic review and psychometric analysis. Health Qual Life Outcomes 2016;14:16.

40 Keller HH, Goy R, Kane S-L. Validity and reliability of screen II (seniors in the community: risk evaluation for eating and nutrition, version II). Eur J Clin Nutr 2005;59:1149-57.

41 Morrison JM, Laur CV, Keller HH. Screen III: working towards a condensed screening tool to detect nutrition risk in community-dwelling older adults using CLSA data. Eur J Clin Nutr 2019;73:1260-9.

42 Ramage-Morin PL, Garriguet D. Nutritional risk among older Canadians. Health Reports 2013;24:3-13.

43 Chiarotto A, Boers M, Deyo RA, et al. Core outcome measurement instruments for clinical trials in nonspecific low back pain. Pain 2018;159:481-95.

44 Ferreira-Valente MA, Pais-Ribeiro JL, Jensen MP. Validity of four pain intensity rating scales. Pain 2011;152:2399-404. 